\section{BDA Update}

\section{Toothbrushing programmes}

The BDA has backed new calls from NICE for oral health programmes in schools, calling on national government to support local authorities to turn the tide on an epidemic of tooth decay.

NICE has recommended councils provide toothbrushing schemes in schools and nurseries in areas where children have poor oral health. Similar schemes exist in both Wales and Scotland, where devolved governments have set out dedicated oral health strategies that include outreach to early years and primary schools, and which have contributed to record breaking falls in decay. Despite progress by many local authorities, there is no equivalent programme in England.

Health officials have claimed that devolution of powers to local authorities in England represents a barrier to rolling out a dedicated national programme.

\section{Soft drink reformulation}

The BDA has welcomed the findings of a study published in the Lancet Public Health which predicts that the impact of a tax on sugar-sweetened drinks - due to come into force in 2018 - could reduce tooth decay by around 270,000 cases every year. ${ }^{1}$

This substantial reduction in dental disease would arise if the softdrinks industry were simply to cut the amount of sugar they add to soft drinks.

It's unknown how the soft drinks industry will respond to the new government tax, but the authors of the Lancet study believe that the greatest health benefits would be achieved from reformulation.

\section{Toothache pressurising A\&E}

The BDA has said dental patients seeking free care at A\&E departments could be costing the NHS as much as $£ 18$ million, as new research shows the government is massively underestimating patient numbers. ${ }^{2}$

A study from Newcastle University reveals that patients attending A\&E with dental problems are now approaching $1 \%(0.7 \%)$ of all attendances. This is ten times official government figures - with over half of the cases identified related to toothache.

Around 14,500 patients with dental problems attended England's A\&Es according to official stats in 2014/15. The BDA has estimated that systematic under-reporting could conservatively place dental attendees at closer to 135,000 patients per year at an annual cost of nearly $£ 18$ million - with over 95,000 cases of toothache coming in at $£ 12.5$ million.

The BDA recently estimated that 600,000 patients a year are seeking treatment from GPs, who like A\&E medics are not equipped to treat dental pain.

New figures revealed this January by the Local Government Association also show that 160 children and teenagers are undergoing tooth extractions under general anaesthesia in hospitals in England every day.

Dentists' leaders have called on Ministers to show leadership and provide a coherent strategy for oral health, and stop pushing patients away with inflation busting increases in NHS charges.

1. Briggs A D M, Mytton O T, Kehlbacher A et al. Health impact assessment of the UK soft drinks industry levy: a comparative risk assessment modelling study. Lancet Public Health 2017; 2: e15-e22. Available at: http://www.sciencedirect.com/science/article/pii/ S2468266716300378

2. Currie C C, Stone S J, Connolly J, Durham J. Dental pain in the medical emergency department: a cross-sectional study. J Oral Rehabil 2016; doi: 10.1111/joor.12462. [Epub ahead of print].
BOOK REVIEW

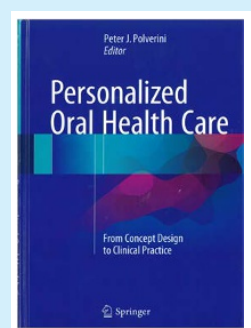

PERSONALIZED ORAL HEALTH CARE: FROM CONCEPT DESIGN TO CLINICAL PRACTICE

Peter J. Polverini

Springer 2015

price $\$ 94.99$ pp 157

ISBN 9783319232973

Personalized oral health care is the first book of its kind to bring the concept of genomic medicine to a wide audience. The book is very informative and interesting from the get go, and the concept of personalised oral healthcare has clearly been well researched.

The book analyses dental care in a way that departs from conventional teaching. Personalized oral health care brings together key research and scientific fact, highlighting the key role of genomic medicine and its application to modern day practice. The book shows how with the latest evidence-based research we can now focus primarily on prevention, risk assessment and early intervention utilising the latest technology. It is a must read for all dentists, and most definitely should form part of the curriculum. Implementation of the proposed theory in the book could result in a much more efficient dental care system in the long term, while being obviously more cost effective.

In order to fully absorb and understand the book, one requires focus and attention as there is a lot of relevant detail. At times I found myself revising fundamental clinical science to fully understand the text, although this was to be expected.

The book is well laid out and easily navigated. There are 12 chapters, each just about the right length to digest. All chapters have sub-headings to help break things down into absorbable amounts. Each chapter starts with an informative abstract which acts as a good overview. The chapters follow a thoughtful and logical sequence, starting with a history of genetics, its role in disease, its role in dentistry, and the future. At the end of each chapter is a rich reference list where one can read and find out more.

Personalized oral health care describes dentistry in an ideal world. I feel that by reading this, all practitioners would gain insight and be in good stead to work towards an optimal healthcare system. I highly recommend it.

R. K. Sondh

\section{The future of orthodontics}

A video has been released showcasing what's in store at the British Orthodontic Society's (BOS') Conference on 14-16 September 2017.

BOC 2017 has the theme 'Back to the future', reflecting the forwardlooking content of many of the presentations, but also embracing the long tradition that makes orthodontics the oldest of all the specialties.

More than 40 top speakers will be sharing their ideas at the

Manchester Conference Centre, including Professors Sabine Ruf and David Bearn discussing research methods.

The film can be viewed at www.bos.org.uk/BOC-Manchester-2017. 